\title{
The Developmental Loss of the Ability of Purkinje Cells to Regenerate Their Axons Occurs in the Absence of Myelin: An In Vitro Model to Prevent Myelination
}

\author{
Lamia Bouslama-Oueghlani, Rosine Wehrlé, Constantino Sotelo, and Isabelle Dusart \\ Institut National de la Santé et de la Recherche Médicale U106, Hôpital de la Salpêtrière, 75651 Paris, France
}

\begin{abstract}
Axonal regeneration in the mammalian CNS is a property of immature neurons that is lost during development. Using organotypic culture of cerebellum, we have shown that in vitro Purkinje cells lose their regenerative capacity in parallel with the process of myelination. We have investigated whether myelination is involved in the age-dependent loss of regeneration of these neurons. By applying a high dose of bromodeoxyuridine in the culture medium of newborn cerebellar slices during the first $3 \mathrm{~d}$ in vitro, we have succeeded in obtaining cultures with oligodendrocyte depletion, together with a lack of ameboid microglia and enhancement of Purkinje cell survival. These cultures, after $14 \mathrm{~d}$ in vitro, are completely devoid of myelin. We have compared the ability of Purkinje cells to regenerate their axons in the presence or absence of myelin. Purkinje cells in cerebellar explants taken at birth, treated with bromodeoxyuridine and axotomized after $7 \mathrm{~d}$ in vitro, survive better than similar neurons in untreated cultures. However, despite the lack of myelin and the enhanced survival, Purkinje cells do not regenerate, whereas they do regenerate when the axotomy is done at postnatal day 0 . Thus, the Purkinje cell developmental switch from axonal regeneration to lack of regeneration does not appear to be regulated by myelin.
\end{abstract}

Key words: axonal regeneration; Purkinje cell; myelin; oligodendrocyte; development; bromo-deoxyuridine

\section{Introduction}

In the immature CNS, neurons can regenerate their axons after axotomy, an ability that is lost with maturation (Hasan et al., 1993; Chen et al., 1995; Li et al., 1995; Dusart et al., 1997; Hafidi et al., 1999; Prang et al., 2001). Molecular changes intrinsic to the neurons or to their axonal microenvironment are considered to be the main causes for the abortive regeneration of mature central neurons in mammals. Environmental inhibitory molecules, such as chondroitin sulfate proteoglycans and tenascin-C, neurite outgrowth inhibitors, are both expressed by adult reactive astrocytes but not by neonatal ones (McKeon et al., 1991). Myelin is also a good candidate because it appears late during development (Reynolds and Wilkin, 1988; Foran and Peterson, 1992), and myelin molecules are negative regulators of regeneration (Schwab and Bartholdi, 1996). Four neurite outgrowth inhibitor molecules (Nogo-A, Tenascin-R, MAG, and oligodendrocyte myelin glycoprotein) have been identified as responsible for the inhibitory role of oligodendrocytes and myelin in axonal regeneration of mature neurons (McKerracher et al., 1994; Mukhopadhyay et al., 1994; Chen et al., 2000; GrandPre et al., 2000; Pesheva and Probstmeier, 2000; Prinjha et al., 2000; Wang et al.,

Received Feb. 24, 2003; revised July 14, 2003; accepted July 22, 2003.

This work was supported by the Institut National de la Santé et de la Recherche Médicale. L.B.-0. is recipient of a doctoral fellowship from the Association pour la Recherche sur le Cancer. C.S. and I.D. are Centre National de la Recherche Scientifique investigators. We thank Drs. M. Meyer, W. Wisden, and J. Oberdick, respectively, for the gifts of CaBP knock-out mice, $\Delta \alpha 6$ lacZ mice, and L7 antibody. We thank Drs. Michel Mallat and Ann Lohof for critical reading of this manuscript.

Correspondence should be addressed to Dr. Isabelle Dusart, UMR7102 NPA, Université Paris VI, Case 12, Bat B, 6éme étage, 9 Quai Saint Bernard, 75005 Paris, France. E-mail: dusart@infobiogen.fr.

Copyright $\odot 2003$ Society for Neuroscience $\quad$ 0270-6474/03/238318-12\$15.00/0
2002). Finally, there are strong assumptions that myelin is involved in the developmental switch that marks the end of the period during which immature neurons can regenerate their axons. For instance, the end of the permissive period for axon regeneration in the spinal cord is coincident with the onset of myelination. Delaying spinal cord myelination delays the end of the permissive period in chick embryos (Keirstead et al., 1992) and in neonatal rats (Savio and Schwab, 1990). More recently, Cai et al. (2001, 2002) have shown that changes in endogenous levels of cAMP are responsible for the switch of the action of myelinderived molecules on axonal regeneration. A developmental decrease of cAMP levels turns the growth-promoting effect of MAG into inhibition, marking the end of the transient developmental period with neuronal ability for axon regeneration (Cai et al., 2001, 2002).

Both in vivo (Gianola and Rossi, 2001) and in vitro studies (Dusart et al., 1997; Ghoumari et al., 2002) of cerebellar Purkinje cells have shown that their regenerative period stops by the end of the first postnatal week. Thus, as is the case in the spinal cord, the developmental switch from a regenerative to a lack of regeneration period seems to be coincident also with the onset of myelination, which in the mouse cerebellum starts at approximately postnatal day (P) 6 (Foran and Peterson, 1992). The question raised by these studies is whether myelin-related molecules are involved in the developmental switch affecting the response to axotomy of maturing Purkinje cells. With this in mind, we designed a simple in vitro model of oligodendrocyte depletion in organotypic slice culture of neonatal mouse cerebellum based on the use of the antimitotic effect of bromodeoxyuridine (BrdU). 
A comparative study between control and treated cultures showed that the antimitotic drug selectively prevents the development of phagocytes and oligodendrocytes and promotes the survival of Purkinje cells. Using these unmyelinated cultures, our axotomy experiments showed that myelin is not the key factor in the regulation of the developmental switch from axonal regeneration to lack of regeneration.

\section{Materials and Methods}

Animals. Unless otherwise specified, newborn Swiss mice (Janvier, Le Genset St. Isle, France) were used in this study. P0 was the day of birth. Calbindin knock-out (CaBP-/-) mice (a kind gift from Dr. Michael Meyer, Martinsreid, Germany) (Airaksinen et al., 1997) were used in most of the coculture experiments to determine more precisely the fate of the regenerating axons of Swiss Purkinje cells immunostained with $\mathrm{CaBP}$ on CaBP-/- slices (Dusart et al., 1997). Homozygous $\Delta \alpha 6$ lacZ mice (strain C57BL/6x129S/v; a kind gift from Dr. William Wisden, Cambridge, UK) (Mellor et al., 1998) were used in this study to label granule cells. In these mice, exon 8 of the $\alpha 6 \mathrm{GABA}_{\mathrm{A}}$ receptor subunit gene was disrupted by homologous recombination, and an internal ribosomal entry site-sLacZ cassette was inserted. Because the $\alpha 6$ subunit is expressed specifically in the granule cells in the cerebellum, immunostaining with the $\beta$-galactosidase ( $\beta$ gal) antibody labels the granule cells in the $\Delta \alpha 6$ lacZ mice (Jones et al., 1997). For each result, at least three animals and 15 slices were used in three independent experiments. The experimental plan was designed in agreement with European Union guidelines for care and use of experimental animals.

In vivo immunohistochemistry of $M B P$. P0 and P3 mice were anesthetized with ice, and P7, P10, and P21 mice with sodium pentobarbital (200 $\mathrm{mg} / \mathrm{kg}$, i.p.). All animals were perfused through the ascending aorta with $4 \%$ paraformaldehyde in $0.12 \mathrm{~m}$ phosphate buffer $(\mathrm{PB}), \mathrm{pH}$ 7.4. Brains were removed, postfixed $4 \mathrm{hr}$, and cryoprotected in $30 \%$ sucrose for $2 \mathrm{~d}$. The cerebella were cut in the sagittal plane $(24-\mu \mathrm{m}$-thick free-floating sections) on a freezing microtome. The sections were then treated as described below for the slice culture.

Slice culture. Cerebellum organotypic cultures of newborn mice (P0) were prepared as described previously (Ghoumari et al., 2002). Briefly, after decapitation, brains were dissected out into cold Gey's balanced salt solution (Invitrogen, Cergy Pontoise, France) containing $5 \mathrm{mg} / \mathrm{ml} \mathrm{glu-}$ cose. Cerebellar parasagittal slices ( $350 \mu \mathrm{m}$ thick) were cut on a McIlwain tissue chopper and transferred onto membranes of $30 \mathrm{~mm}$ Millipore culture inserts with $0.4 \mu \mathrm{m}$ pore size (Millicell; Millipore, Bedford, MA). Slices were maintained in culture in 6 -well plates containing $1 \mathrm{ml}$ of medium at $35^{\circ} \mathrm{C}$ in an atmosphere of humidified $5 \% \mathrm{CO}_{2}$. The nutrient medium was composed of $50 \%$ basal medium with Earle's salts (Invitrogen), 25\% HBSS (Invitrogen), 25\% horse serum (Invitrogen), L-glutamine (1 mM), and $5 \mathrm{mg} / \mathrm{ml}$ glucose (Stoppini et al., 1991).

Some cultures were transected with two needles under a dissecting microscope. The two parts were gently separated to ensure a complete axotomy before being reapposed. In some experiments, the dorsal parts were apposed to ventral halves of $\mathrm{P} 0$ calbindin knock-out (CaBP-/-) cerebellar slices (Dusart et al., 1997; Ghoumari et al., 2002).

Oligodendrocyte depletion: exposure of cerebellar slices to BrdU. BrdU $\left(1.5 \times 10^{-4} \mathrm{M}\right.$; Sigma, St. Louis, MO) dissolved in $\mathrm{NaCl}(9 \mathrm{gm} / \mathrm{l})$ was incorporated into the nutrient medium from the time of culture until the third day in vitro. The BrdU concentration used to prevent myelin formation in cerebellar slices has been defined previously (Younkin and Silberberg, 1973). We tested different times of exposition to BrdU and found that the treatment during the first $3 \mathrm{~d}$ of culture is the shortest time of exposition to BrdU, leading to oligodendrocyte depletion. We did not obtain the same time window of treatment as in the study of Younkin and Silberberg (1973), probably because they used rats instead of mice.

Antibodies and lectin. Rabbit polyclonal antibodies against CaBP (diluted 1:5,000; Swant, Bellinzona, Switzerland) and rabbit polyclonal antibodies L7 (diluted 1:5,000; a kind gift from Dr. John Oberdick, Columbus, $\mathrm{OH}$ ) (Oberdick et al., 1988) were used to visualize Purkinje cells (Dusart et al., 1997). Mouse monoclonal antibodies against parvalbumin (diluted 1:10,000; Sigma) were used to visualize Purkinje, basket, and stellate cells (Celio, 1990). Mouse monoclonal antibodies against NeuN (diluted 1:500; Chemicon, Hampshire, UK) stain all neurons in the cerebellum, except Purkinje cells (Mullen et al., 1992). Rabbit polyclonal antibodies against $\beta$ gal (diluted 1:1,000, Cappel Cooper Biomedical, Malvern, PA) were used to stain granule cells in the $\Delta \alpha 6$ lacZ mice.

Mouse monoclonal antibodies against MBP (diluted 1:2,000; Boehringer Mannheim, Indianapolis, IN) were used to visualize myelin and mature oligodendrocytes (Dusart et al., 1997). Rabbit polyclonal antibodies against GFAP (diluted 1:10,000; Dako, Glostrup, Denmark) were used to label astrocytes (Dusart et al., 1997). Isolectin B4 from Griffonia simplicifolia coupled with FITC (diluted $0.02 \mathrm{mg} / \mathrm{ml}$; Sigma) was applied to visualize microglial cells, macrophages, and endothelial cells (Streit and Kreutzberg, 1987).

Staining procedures. The cultures and cocultures were fixed in $4 \%$ paraformaldehyde in $\mathrm{PB}(0.1 \mathrm{M}$; $\mathrm{pH}$ 7.4) for $1 \mathrm{hr}$ at room temperature (RT) at intervals ranging from 7 to $14 \mathrm{~d}$ in vitro (DIV). After washing in PBS (Invitrogen), the slices were taken off Millicells. When antibodies against MBP were used, slices were first immersed in Clark's solution (95\% ethanol-5\% acetic acid) for $20 \mathrm{~min}$ at $4^{\circ} \mathrm{C}$ to extract some of the lipids and, thus, make the MBP antigens accessible for the antibodies; then, the slices were washed several times with PBS. In all cases, the slices were incubated for $1 \mathrm{hr}$ in PBS containing $0.2 \%$ gelatin, $0.1 \%$ sodium azide (PBSGA), and lysine $(0.1 \mathrm{M})$, before applying the primary antibodies, diluted in PBSGA overnight. The primary antibodies were revealed with the following secondary antibodies: goat anti-mouse CY3 (1:200 dilution; Jackson ImmunoResearch Laboratories, Inc., West Grove, PA), goat anti-rabbit CY3 (1:200 dilution; Jackson ImmunoResearch Laboratories, Inc.), or sheep anti-rabbit FITC (1:200 dilution; Silenus Laboratories, Hawthorne, Australia). After a $2 \mathrm{hr}$ incubation in PBSGA containing the secondary antibodies, the slices were washed several times in PBS, mounted in mowiol (Calbiochem, France Biochem, Meudon, France), and analyzed using a Leica DMR microscope equipped with a coolscan camera (Princeton Instruments, Evry, France). Images were captured on a Dell computer using Metaview software (Universal Imaging Corporation, West Chester, PA). Finally, figure plates were prepared using Adobe Photoshop version 6.0 software (Adobe System, Inc).

Electron microscopy. After 14 DIV, slices were fixed in culture medium added with increasing doses of fixative containing $1 \%$ paraformaldehyde and $1 \%$ glutaraldehyde in $\mathrm{PB}(0.4 \mathrm{M}$; $\mathrm{pH}$ 7.4) from one-fourth of the volume to full fixative for $2 \mathrm{hr}$ at RT. The slices were postfixed in a solution containing $2 \%$ osmium tetroxide in PB for $2 \mathrm{hr}$ at RT. After en bloc staining with a solution containing $2 \%$ uranyl acetate in $\mathrm{PB}(0.2 \mathrm{M}$; $\mathrm{pH}$ 4.6) for $45 \mathrm{~min}$ at $4^{\circ} \mathrm{C}$, the slices were dehydrated in graded ethanols and flat-embedded in Araldite. Three blocks of control and BrdU-treated slices were sectioned with a Reichert-Jung ultramicrotome. The first complete $0.5-\mu \mathrm{m}$-thick section was stained with $0.5 \%$ toluidine blue (Merck, Darmstadt, Germany). The ultrathin sections were stained with uranyl acetate and lead citrate and examined with a Philips CM100.

Myelin and oligodendrocyte quantification. Oligodendocytes send out extensions of their cytoplasmic membrane, each of which forms a segment of sheathing around an axon, called the internode (see Fig. 2C); internodes are separated by spaces where myelin is lacking, in the nodes of Ranvier. Thus, on a section immunolabeled with an antibody raised against MBP, two elements can be visualized, the oligodendrocytes (Fig. $2 A, B$ ) and the internodes (Fig. 2C). Because each oligodendrocyte myelinates many axons, internodes are always seen in packs. A pack of internodes is defined as a set of internodes that are close to each other (Fig. 2C). To assess the state of myelination, internodes and mature oligodendrocytes (those MBP positive) were quantified under a fluorescence microscope (Leica DMR). Three classes of slices were defined. The first class (I) included the slices with a small number of oligodendrocytes and of packs of internodes ( $<15$ of each; Fig. $2 G$ ). The second class (II) included slices containing $>16$ oligodendrocytes or 16 internode packs but $<20$ packs of internodes (Fig. $2 A$ ). The third class (III) included slices containing $>21$ packs of internodes (Fig. $2 E$ ). Thus, class III represents the slices with a maximum amount of myelination.

Quantification of Purkinje cell survival. To determine the Purkinje cell survival in cultures, those neurons were immunostained with an antibody against $\mathrm{CaBP}$ and quantified under a fluorescence microscope 
(Leica DMR). Three groups of slices were defined (Ghoumari et al., 2002). Briefly, the first group (I) included the slices with few and dispersed Purkinje cells (i.e., those with no compact group of $>20$ Purkinje cells). The second group (II) included the slices containing one or two compact groups of $>20$ Purkinje cells. The third group (III), with maximum Purkinje cell survival, included the slices containing more than three compact groups of at least 20 Purkinje cells or one compact group of $>50$ Purkinje cells. For each case, the percentages of slices included in groups I, II, and III were calculated.

$\alpha 6$ Granule cell quantification. To determine whether the BrdU treatment has a permanent effect on the granule cell population, we have used $\Delta \alpha 6$ lacZ mice. P0-P14 DIV slices (control and treated) were immunostained with $\beta$ gal antibody that labels granule cells in those mice. On each slice, the area with the highest number of $\beta$ gal immunoreactive cells was selected, and one picture of this area was taken at the $40 \times$ magnification $\left(93,150 \mu \mathrm{m}^{2}\right)$. $\beta$ galpositive cells were counted in the picture, and the cell density (number of $\beta$ gal-positive cells per $100,000 \mu \mathrm{m}^{2}$ ) was calculated for each slice. Then, the means of cell densities and the SEM were calculated for control and treated slices. Data were statistically analyzed using the Student's $t$ test.

Quantification of molecular layer interneu-
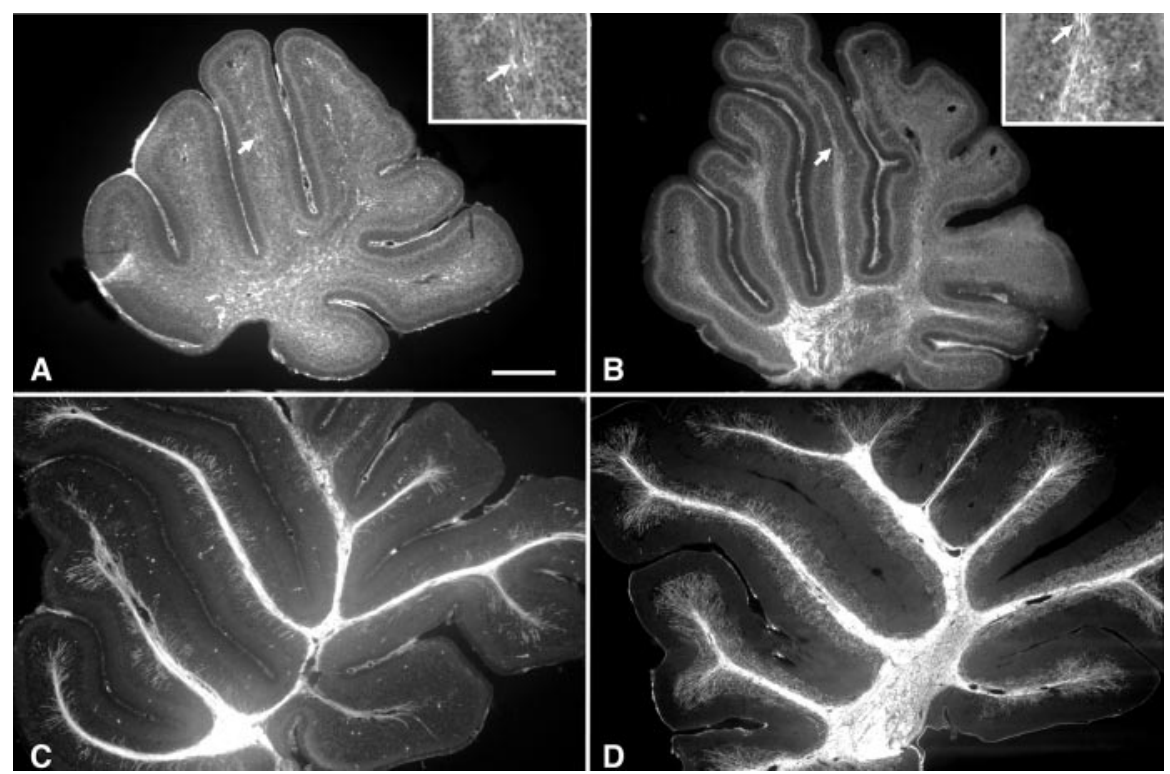

Figure 1. Mouse developmental myelination in vivo. Parasagittal slices of cerebella at P3 $(A), P 7(B), P 10(C)$, and P21 (D) immunostained with an antibody against MBP. $A, A t P 3$, numerous MBP-positive cells are present in the area of the deep nuclear neurons and few in the white matter of the folia (see high magnification in the inset). $B$, At P7, myelinated segments can be observed in the white matter of the folia (see high magnification in the inset). C, At P10, almost all the axes of the folia are myelinated, and some myelin segments start to appear in the granule cell layer. D, At P21, the cerebellum is almost fully myelinated. Note that MBP-positive segments are present at high density in the granular cell layer. The arrows in $A$ and $B$ indicate to the areas presented at higher magnification in their respective insets. Scale bar: $A-D, 220 \mu \mathrm{m}$; insets, $75 \mu \mathrm{m}$.

rons. Because there are no specific markers for stellate and basket cells, we used anti-parvalbumin antibodies that label these interneurons and mature Purkinje cells. Using double labeling with antibodies against parvalbumin (revealed in red) and against CaBP (revealed in green), we were able to differentiate Purkinje cells (double labeled, yellow) from stellate and basket cells (red). On each slice, the area with the highest number of stellate cells and basket cells were selected, and two pictures were taken at $40 \times$ magnification $\left(93,150 \mu \mathrm{m}^{2}\right)$ with a Coolscan camera. In Adobe Photoshop, the gray picture from the CaBP immunostaining was copied into the green layer of a red, green, and blue image, and the parvalbumin immunostaining picture was copied into the red layer. The red cells were counted on each assembled image. The cell density (number of red cells per 100,000 $\mu \mathrm{m}^{2}$ ) was calculated for each slice. Then, the means of cell densities and the SEM were calculated for control and treated slices. Data were analyzed using the Student's $t$ test.

Quantification of the regeneration in presence or absence of BrdU. To evaluate the regeneration of Purkinje cell axons in controls and BrdUtreated cultures, we quantified the surfaces covered by the regenerative axons and their lengths as described previously (Ghoumari et al., 2002). However, we did not use parvalbumin staining to delineate the coculture interfaces, because they were double labeled with MBP staining to check for the presence or the absence of myelin. However, because in many slices the fusion line between cocultures could be identified, we used this criterion in our quantifications. This criterion can be applied not only to cocultures but also to axotomized explants. We first eliminated all the slices on which this interface could not be defined without ambiguity [control axotomy (Ctrl-Axt) at 0 DIV, 36 slices; BrdU-Axt at 0 DIV, 17 slices; Ctrl-Axt at 7 DIV, 18 slices; BrdU-Axt at 7 DIV, 44 slices]. The other slices, on which the needle cut was obvious (Ctrl-Axt at 0 DIV: seven animals, 13 slices; BrdU-Axt at 0 DIV: six animals, 25 slices; CtrlAxt at 7 DIV: seven animals, 24 slices; BrdU-Axt at 7 DIV: nine animals, 24 slices), were digitally scanned with a Coolscan camera, and the images were analyzed using Metamorph software. The contour of the area covered by the regenerative axon processes was acquired by hand with computer-aided filling, and the surface was calculated by Metamorph. This measure takes into account both regenerative axon lengths and numbers. In addition, the length of the longest axon per culture was measured on the acquired pictures. The means and the SEM were calculated. Data were analyzed using the Student's $t$ test.

\section{Results}

The aim of the present study was to determine whether myelination is involved in the regulation of the developmental switch that converts the capacity of Purkinje cells to regenerate their axons into a permanent failure. To this aim, we compared the timing of this change in cultures with or without myelin. First, we had to show that in cultures taken from P0 cerebellum and maintained in vitro for 7 or $14 \mathrm{~d}$ (DIV), myelination and the developmental switch on Purkinje cell regeneration occur. In parallel, we also had to prove that the BrdU treatment for 3 consecutive days ablates oligodendrocytes and prevents myelin formation. Finally, we analyzed whether the BrdU treatment interferes with the other cell populations of the cerebellar cortex.

\section{Cerebellar myelination: onset in vivo and in vitro}

We first determined the precise timing of the myelination in the mouse cerebellum because little information was available previously. At P0, the cerebellum was totally devoid of MBP staining. $\mathrm{MBP}$-positive cells appeared in the central deep white matter of the $\mathrm{P} 3$ vermis, in which small packs of myelinated segments were distributed within and around the deep cerebellar nuclei (Fig. $1 A)$. At this age, a few MBP-positive cells were also present in the prospective white matter axes of the folia, including in the most dorsal lobules (Fig. 1A, inset). By P7, the myelination had progressed, with the appearance of numerous packs of myelinated segments in the central white matter axes of the lobules (Fig. $1 B$ and inset). By P10, myelinated segments started to appear in the granule cell layer (Fig. 1C) and were present in high density both in the white matter and in the granule cell layer at P21 (Fig. 1D). These results clearly demonstrate that myelination in the cerebellum starts from P3. 

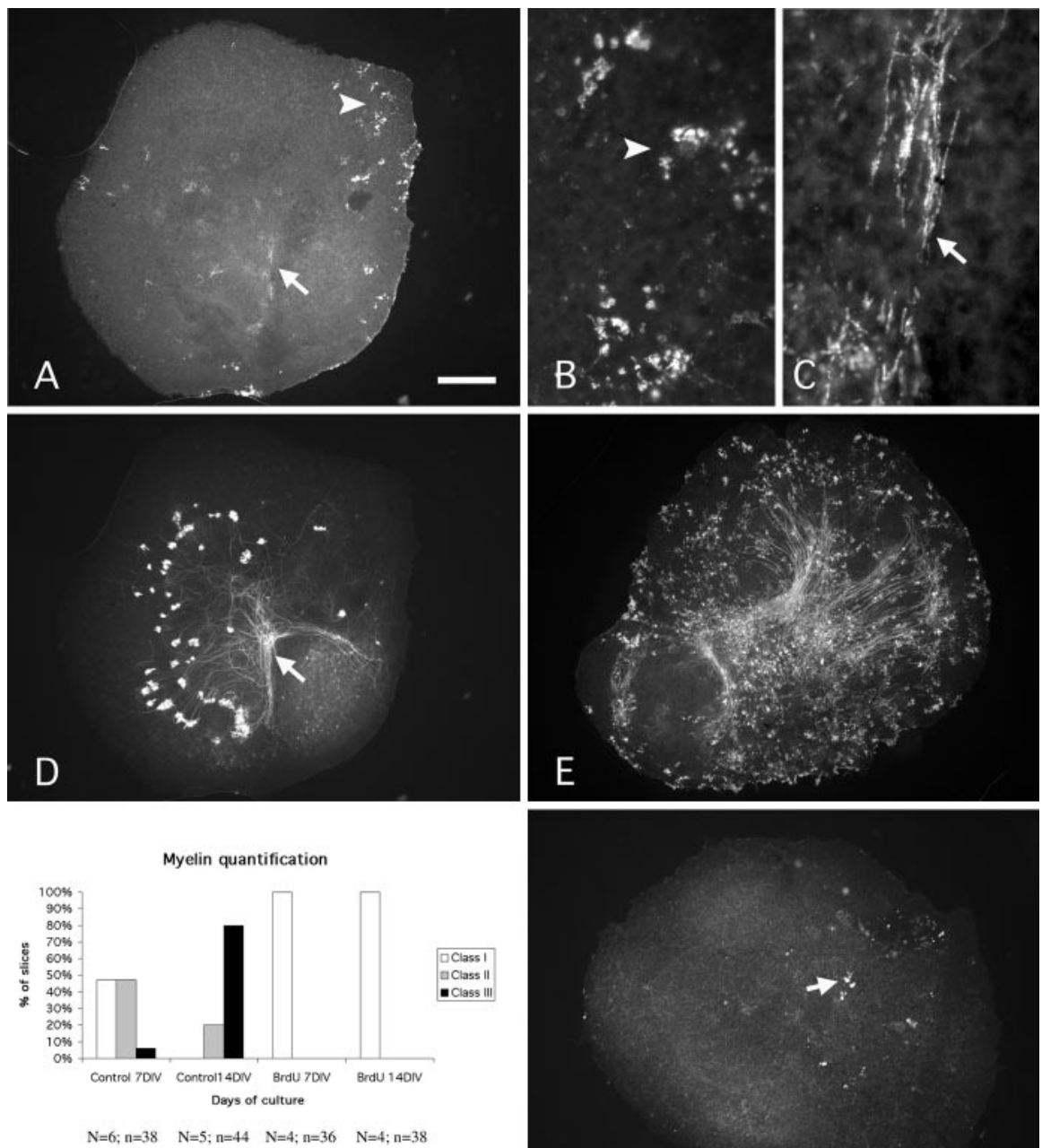

$\mathrm{F}$

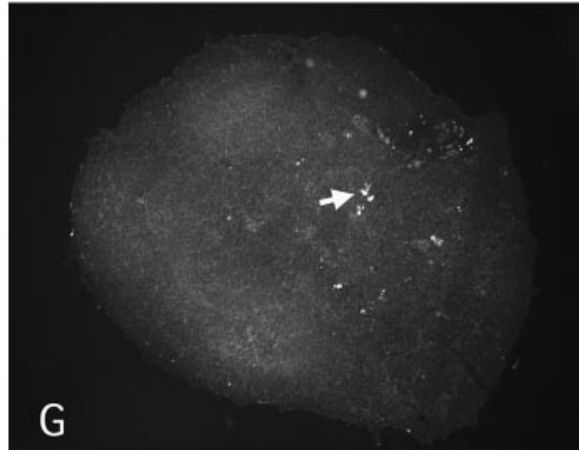

Figure 2. Myelination and inhibition of myelination in vitro. $A-D$, Photomicrographs of a $P 0$ cerebellar slice maintained 7 DIV and double labeled with antibodies against $\operatorname{MBP}(A-C)$ and $\mathrm{CaBP}(D)$. MBP-positive oligodendrocytes (arrowhead) and segments (arrow) are present $(A)$. Note that the packs of MBP-positive segments are numerous in the area of deep nuclear neurons revealed by the presence of numerous Purkinje cell axon terminals $(A, D$, arrows). $B$, Higher magnification of an area of $A$ showing MBPpositive oligodendrocytes. Arrowheads in $A$ and $B$ point to the same area. C, Higher magnification of the area indicated by the arrow in $A$, showing MBP-positive segment packs. Arrows in $A$ and $($ point to the same area. E, Photomicrograph of a P0-14 DIV slice immunostained with an antibody against MBP showing the high number of MBP-positive cells and segments in comparison with the P0-7 DIV slice (A).F, Quantitative evaluation of myelination. The three classes of slices (I, II, and III) were defined according to the number of MBP-positive cells and segments. Class I included the slices with a small number of oligodendrocytes and of packs of internodes $(<15$ of each; $G$ ). Class II included slices containing $>16$ oligodendrocytes or 16 internode packs but $<20$ packs of internodes $(A)$. Class III included slices containing $>21$ packs of internodes $(E)$. N, Number of animals; $n$, number of slices. $G$, Photomicrograph of a P0 -14 DIV BrdU-treated slice immunostained with an antibody against MBP. Note that only a few oligodendrocytes (arrow) can be observed. Scale bar: $A, D, E, G, 270 \mu \mathrm{m} ; B, C, 30 \mu \mathrm{m}$.

In vitro, after $7 \mathrm{DIV}, \mathrm{MBP}$-positive oligodendrocytes and internodes were observed (Fig. $2 A$ ). Oligodendrocytes were round MBP-positive cells with few processes (Fig. $2 B$ ), and myelin internodes were thin elongated MBP-positive elements (Fig. 2C). MBP-positive internodes usually appeared in packs (Fig. 2A,C) that were also more numerous in the area of deep nuclear neurons, in which Purkinje cell axons terminate (Fig. 2A,D). After 14 $\mathrm{DIV}$, the number of MBP-positive cells and internodes increased, and they are observed all over the slice (Fig. $2 E$ ).

To evaluate the stage of myelination in the cultures, three classes of slices were defined, as described in Materials and Methods. Briefly, the first class (I) included the slices with fewer than 15 oligodendrocytes and fewer than 15 internode packs (Fig. 2G).
The second class (II) included the slices containing $>16$ oligodendrocytes or 16 internode packs but $<20$ internode packs (Fig. 2A). The third class (III), with a maximum of myelination, included the slices containing $>21$ internode packs (Fig. 2E). This quantification reflects the rate of myelination observed in slices. At 7 DIV, $53 \%$ of the slices already contained MBP-positive elements: $47 \%$ were in class II and 6\% in class III (Fig. 2 F). Myelination greatly increased during the second week, and at 14 DIV, the majority of the slices was in class III ( $80 \%$; Fig. 2 F). Thus, myelination has begun at 7 DIV and is greatly increased during the second week of culture.

\section{BrdU provoked depletion of oligodendrocytes in vitro}

To provoke oligodendrocyte cell death, we applied BrdU during the first $3 \mathrm{~d}$ of culture, during active oligodendrocyte division (see Materials and Methods). BrdU at high concentrations leads to the death of all dividing cells. Treated slices at 7 DIV and 14 DIV were completely devoid of MBP-positive elements, and only in some $\mathrm{P} 0+14$ DIV slices were a few MBPpositive elements observed (Fig. 2G). All the BrdU-treated slices were in class I at 7 DIV and 14 DIV (Fig. 2F), whereas 80\% of the control slices at 14 DIV were in the class III. To corroborate the immunohistochemical results, we performed an ultrastructural study to provide further evidence of the lack of myelin in the treated slices. The electron microscopic study was performed on P0 cerebellar slices, treated or untreated, and maintained in vitro for $14 \mathrm{~d}$.

In all control slices, we identified areas composed mainly of longitudinally oriented axonal profiles and glial cells (Fig. $3 A)$. These areas corresponded to the cerebellar white matter and contained the Purkinje cell axons which, with the exception of some others emerging from a few deep nuclear neurons, were the only myelinated axons in the cerebellar culture (Dusart et al., 1997). The myelin sheaths around the Purkinje cell axons were thinner than in the adult cerebellum, because less than a dozen major dense lines formed the compact spiraled sheet. However, the spacing of nodes of Ranvier along the axon appeared normal, because the density of the nodes (Fig. $3 A, D$ ) corresponded to that observed in mouse cerebellum. Thin myelin sheaths were occasionally seen surrounding perikarya of cortical interneurons, particularly granule cells (Fig. $3 B$ ), as known to occur in the cerebellum (Cooper and Beal, 1977). In addition, we also observed abundant thin myelinated fibers undergoing degeneration in control cultures (Fig. $3 A$ ). In contrast to the control cultures, the BrdU-treated cultures were completely devoid of myelin sheaths around axons, interneuronal perikarya, or ne- 
crotic debris. Nevertheless, areas containing almost exclusively longitudinally oriented axons and glial cells, corresponding to pseudo-white matter, were constantly encountered in these cultures (Fig. 3C,E). Thus, whereas in control slices myelinated axons were systematically observed, they were completely absent in the treated slices, providing further evidence that the oligodendrocyte depletion model truly provides a cellular milieu exempt from myelin.

Effects of BrdU on the different cellular populations of the cerebellar cortex

Other cell populations of the cerebellar cortex could be affected by the BrdU treatment, either directly if they also proliferate during this time window (microglia, astrocytes, granule, basket, and stellate cells) or indirectly, as could be the case for Purkinje cells. We, therefore, investigated the effect of the treatment on the other cellular populations of the organotypic culture.

\section{Astrocytes}

P0 + 7 DIV control and BrdU-treated slices were immunostained with a GFAP antibody that specifically labels astrocytes. Because of the high density of GFAP-positive profiles encountered in both types of slices, we did not attempt quantification of the number of astrocytes. Nevertheless, their density as measured by the surface area covered by these profiles was greater in the treated slices (Fig. 4, compare $A, B$ ). More importantly, there was a remarkable qualitative difference between astrocytes in both types of slices. In the treated ones, the GFAP-positive processes were much longer than in control slices (Fig. $4 A, B$ ). This hypertrophy of astrocytic processes indicates that they are more reactive. Thus, although our data do not allow us to conclude that there was an increased number of astrocytes with BrdU treatment, they strongly indicate that the reactive gliosis that characterizes control organotypic culture (Dusart et al., 1997) is increased by the treatment.

\section{Microglial cells}

Two types of cells were labeled with isolectin B4, the microglial or macrophagic cells, and the endothelial cells. The endothelial cells were easily identifiable because of their elongated shape. These endothelial cells were present in control and in treated slices at the same apparent density (data not shown). In contrast, a clear difference in the microglial and macrophagic cell population was observed between control and treated slices: only a few isolectin B4-positive cells were present in BrdU-treated slices (Fig. 4D) when compared with control slices (Fig. 4C). In addition, there
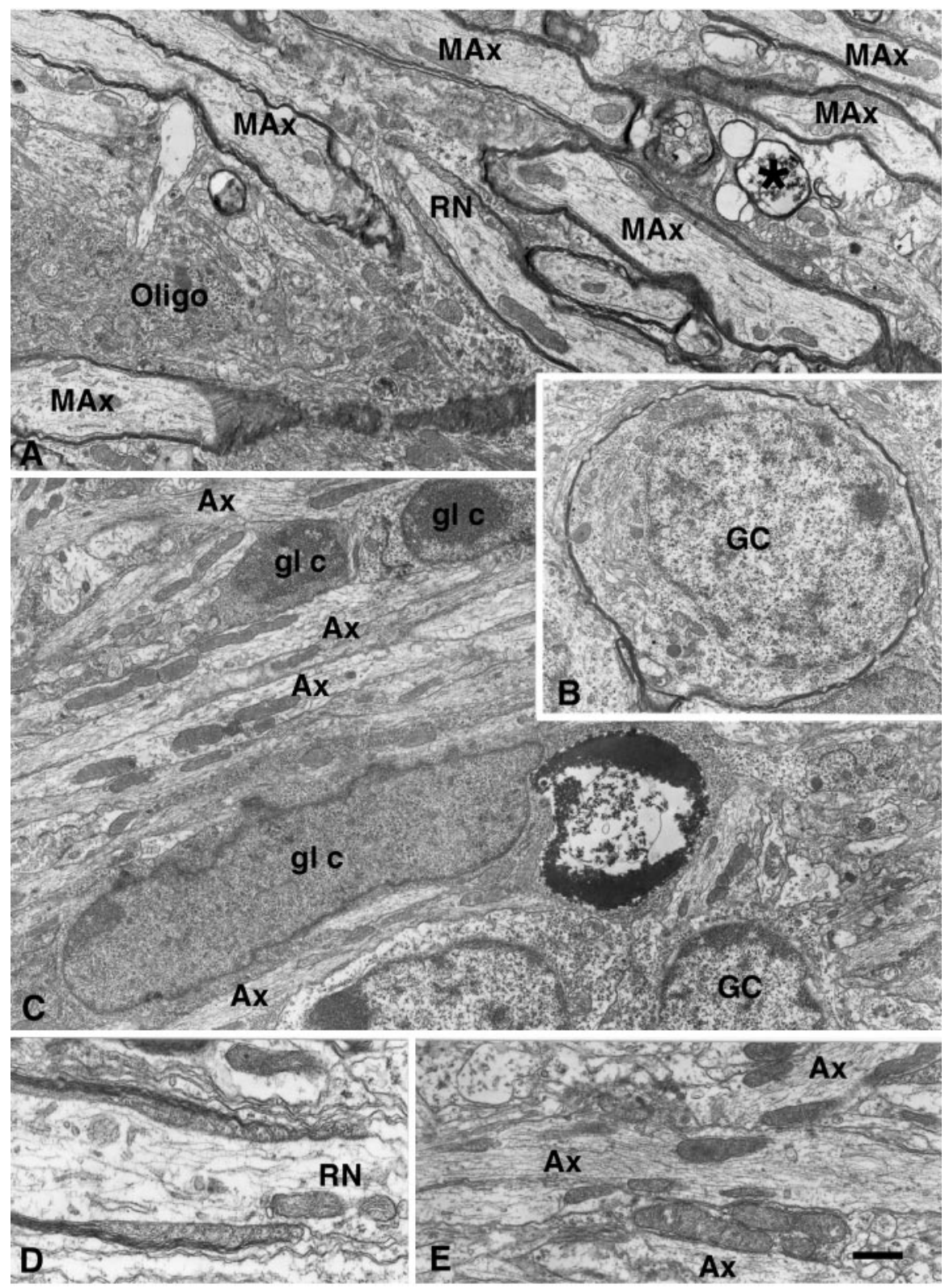

Figure 3. Electron micrographs of $\mathrm{P} 0-14 \mathrm{DIV}$ cerebellar slices treated with $\operatorname{BrdU}(C, E)$ or untreated $(A, B, D) . A$, On a control slice, numerous myelinated axons (MAx) and few oligodendrocytes (Oligo) can be observed. The asterisk indicates the presence of a degenerating myelinated axon. RN, Ranvier node. $B$, The granule cell $(\mathrm{GC})$ shown in this micrograph is myelinated. $C, 0$ n a treated slice, no myelin can be detected either around axons (Ax) present among glial cells ( $\mathrm{gl} \mathrm{c}$ ) or around granule cells (GC). D, Electron micrograph showing a Ranvier node (RN) in a control slice. E, Electron micrograph showing the presence of numerous nonmyelinated axons (Ax) on a treated slice. Scale bar: $A, E, 1 \mu \mathrm{m} ; B, 1.5 \mu \mathrm{m} ; C, 1.25 \mu \mathrm{m} ; D, 0.5 \mu \mathrm{m}$.

was also an important qualitative difference: in control slices, the majority of the isolectin B4-positive cells were round or ameboid-shaped, with a macrophage-like appearance (Fig. 4C), indicative of reactive microglial cells or of macrophages. In contrast, in BrdU-treated slices, the isolectin B4-positive cells were ramified with numerous processes (Fig. 4D). This morphology corresponds to that of resting microglial cells. Thus, BrdU treatment suppresses most of the round ameboid microglial cells.

\section{Purkinje cells}

Previous results with Purkinje cells in slice culture have revealed that these neurons are very sensitive to the in vitro conditions and pass through a developmental critical period of programmed cell death (Ghoumari et al., 2000, 2002). Because their survival is 

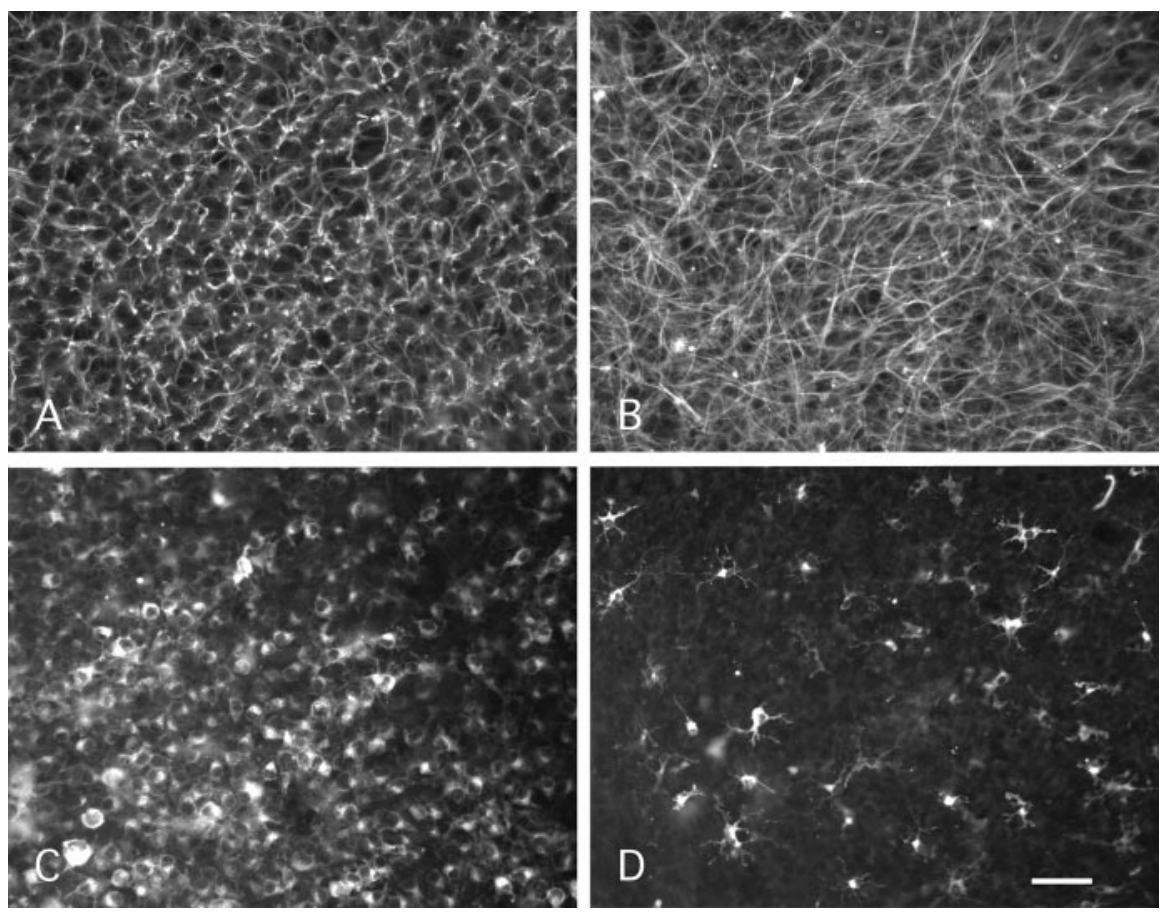

Figure 4. Effects of BrdU treatment on astrocytes and microglial cells. $A, B$, Photomicrographs of P0 -7 DIV slices stained with anti-GFAP antibodies. Control slice $(A)$ and treated slice $(B)$ show numerous GFAP-positive processes. Note that the density and the size of GFAP-positive processes are higher in the treated slice $(B)$ than in the control slice $(A)$. C, D, Photomicrographs of P0 -7 DIV slices stained with isolectin B4-FITC. The control slice ( $C$ ) shows a high number of microglial cells, most with a round morphology. In contrast, in a BrdU-treated slice ( $D$ ), the majority of isolectin B4-positive cells is ramified showing numerous processes. Note that the number of isolectin B4-positive is higher in the control slice ( $C$ ) than in the treated slice ( $D$ ). Scale bar: $A, B, 40 \mu \mathrm{m} ; C, D, 70 \mu \mathrm{m}$.

essential for the aim of our study, we paid special attention to their fate in the BrdU-treated slices. To correlate survival and location of Purkinje cell axons with formation or prevention of myelin, most results were obtained from double-labeled cultures, with anti-CaBP to identify Purkinje cells (Fig. 5C,D) and antiMBP to evaluate the state of myelination of their axons (Fig. $5 A, B)$. Surprisingly, the treatment with BrdU develops culture conditions in which the death of Purkinje cells is nearly abolished. As a result, the number of surviving Purkinje cells is much greater in treated than in untreated cultures (Fig. 5, compare $C$, $D)$. All the treated slices were in group III (see Materials and Methods; Fig. 5E), contrary to what happened with control slices (Fig. 5E). The density was so greatly increased that it was often difficult to visualize the dendritic arbors of the surviving neurons (Fig. 5D), raising the question of their characterization. To eliminate any possibility of ectopic expression of CaBP (a cerebellarselective marker of Purkinje cells), some of the treated cultures were double labeled with anti-CaBP and anti-L7 (a specific marker for Purkinje cells). The double labeling corroborated that all CaBP-positive neurons (Fig. $6 \mathrm{~A}, \mathrm{C}$ ) were also L7 positive (Fig. $6 B, C)$, although in some cells the level of L7 expression was much lower than the level of CaBP expression (Fig. $6 A-C$ ). Therefore, conditions created by the BrdU treatment are extremely favorable for the survival of Purkinje cells in P0 + 14 DIV cultures.

General pattern of neuronal distribution in cerebellar culture NeuN antibody is known to label all neurons of the cerebellar cortex, with the exception of Purkinje cells (Mullen et al., 1992). Thus, the use of cerebellar slices double labeled with anti-NeuN and anti-CaBP antibodies allowed us to evaluate neuronal survival and distribution in control and treated cultures. In both types of cultures, the numerous NeuNpositive cells were heterogeneously distributed and were more frequently seen in regions neighboring CaBP-positive Purkinje cells (Fig. 6D,E). The discrimination between molecular layer interneurons (basket and stellate cells) and granule cells was based on the different size of their respective cell bodies and also by the use of cell markers. Double immunostaining with $\mathrm{CaBP}$ and parvalbumin was performed to identify stellate and basket cells, and $\beta$ gal immunostaining on $\Delta \alpha 6$ lacZ mouse cerebellar slices were used to identify mature granule cells.

\section{Stellate and basket cells}

Anti-parvalbumin antibodies label mature Purkinje cells and molecular layer interneurons (stellate cells and basket cells), whereas anti-CaBP antibodies label exclusively Purkinje cells. In double (antiparvalbumin/anti-CaBP) immunolabeled P0 + 14 DIV slices, most Purkinje cells were double stained and appeared in yellow (Fig. $6 H$ ); only a few were parvalbumin negative and appeared in green (CaBP positive; Fig. 6F,H). Basket and stellate cells were only labeled by antiparvalbumin antibodies and appeared in red (Fig. 6G,H). The occurrence in both control and treated cultures of a few CaBP-positive/paralbumin-negative Purkinje cells could be explained by the already established fact that the developmental acquisition of parvalbumin expression is often delayed under in vitro conditions. In any case, the combination of markers used here allowed us to identify with certainty stellate and basket cells. These interneurons could be observed in areas containing Purkinje cell dendrites (Fig. 6G,H), areas equivalent to cortical molecular layer. Such parvalbumin-positive/ CaBP-negative neurons were scarce in control and treated cultures. Quantitative analysis of stellate and basket cell densities in control and treated slices were performed as described in Materials and Methods. The mean cell densities $( \pm$ SEM) were $7 \pm 1.6$ per $10^{5} \mu \mathrm{m}^{2}$ in BrdU-treated slices (four animals, 18 slices) and $9 \pm 1.8$ in control slices (three animals, 15 slices). These densities were not significantly different ( $t$ test; $p>0.05$ ). We can, therefore, conclude that the BrdU treatment has no effect on the development and survival of stellate and basket cells in the $\mathrm{P} 0+14$ DIV cerebellar cultures.

\section{Granule cells}

During cerebellar development in vivo, granule cells originate from precursor cells of the external granular layer (EGL) that proliferate during the first two postnatal weeks (Miale and Sidman, 1961). Thus, during the treatment of the cultures with BrdU, EGL cells were actively proliferating. It was, therefore, crucial to investigate whether the application of BrdU to the culture medium significantly altered the granule cell population. These investigations were performed in slices taken from P0 cerebella of $\Delta \alpha 6$ lacZ transgenic mice, which allows identification of granule cells with $\beta$ gal immunostaining (see Materials and Methods) (Jones et al., 1997). However, because the expression of the $\mathrm{GABA}_{\mathrm{A}}$ receptor $\alpha 6$ subunit is a late process in granule cell dif- 
ferentiation (Mellor et al., 1998), the study of the cultures was only possible in P0 + 14 DIV. Corroborating the results obtained with NeuN immunohistochemistry, the distribution of the $\alpha 6$-positive cells was heterogeneous in control and treated slices, and granule cells were numerous in regions containing Purkinje cells (data not shown). Quantitative analysis of granule cell densities in control and treated slices were performed on $\beta$ gal immunostained slices of $\Delta \alpha 6$ lacZ mice (see Materials and Methods). The mean ( \pm SEM) granular cell densities were 197 \pm 10 per $10^{5} \mu \mathrm{m}^{2}$ in BrdU-treated slices (four animals, 33 slices) and $180 \pm 12$ in control slices (four animals, 33 slices). This difference was not significant ( $t$ test; $p>0.05)$. Furthermore, at the ultrastructural level, numerous granule cells were observed in BrdU-treated slices as well as in control slices. Thus, BrdU treatment did not alter the density of granule cells after 14 DIV. These quantitative studies do not preclude the possibility of a high rate of death of dividing granule cell precursors during the $3 \mathrm{~d}$ of BrdU treatment. However, because these days were the first 3 DIV, and in the presence of a large number of surviving Purkinje cells and of their plausible secretion of mitogen factors, including sonic hedgehog (Dahmane and Ruiz-i-Altaba, 1999), regeneration of granule cell precursors is most possible.

In conclusion, the $3 \mathrm{~d}$ treatment of $\mathrm{P} 0$ cerebellar slices with BrdU successfully provided relatively mature $(\mathrm{P} 0+14 \mathrm{DIV})$ cultures devoid of myelin. Moreover, our comparative study of control and treated cultures showed important qualitative and quantitative changes. In addition to the expected absence of oligodendrocytes and myelin, BrdU also prevented the proliferation of phagocytes, increased the normally occurring process of astrogliosis in the cerebellar explants, and, notably, increased the survival of Purkinje cells.

\section{Regeneration of P0 Purkinje cell axons} maturing in vitro is age dependent We have shown previously that Purkinje cells in explants taken from P0 cerebellum are able to regenerate their lesioned axons, whereas this regenerative capacity is totally absent in Purkinje cells taken from P7 cerebellum (Dusart et al., 1997; Ghoumari et al., 2002). Because the developmental pace of neurons could differ from in vivo to in vitro conditions, we tested whether P0 Purkinje cells maturing in vitro would also lose their regenerative capacity. P0 cerebellar slices were divided into a dorsal and a ventral half at explantation, amputated of their ventral halves, and apposed to ventral halves of $\mathrm{P} 0$ explants taken, in most instances, from $\mathrm{CaBP}-/$ - cerebellum. After 7 DIV, despite their high survival rates in intact slices, axotomized Purkinje cells massively died, but the survivors in-
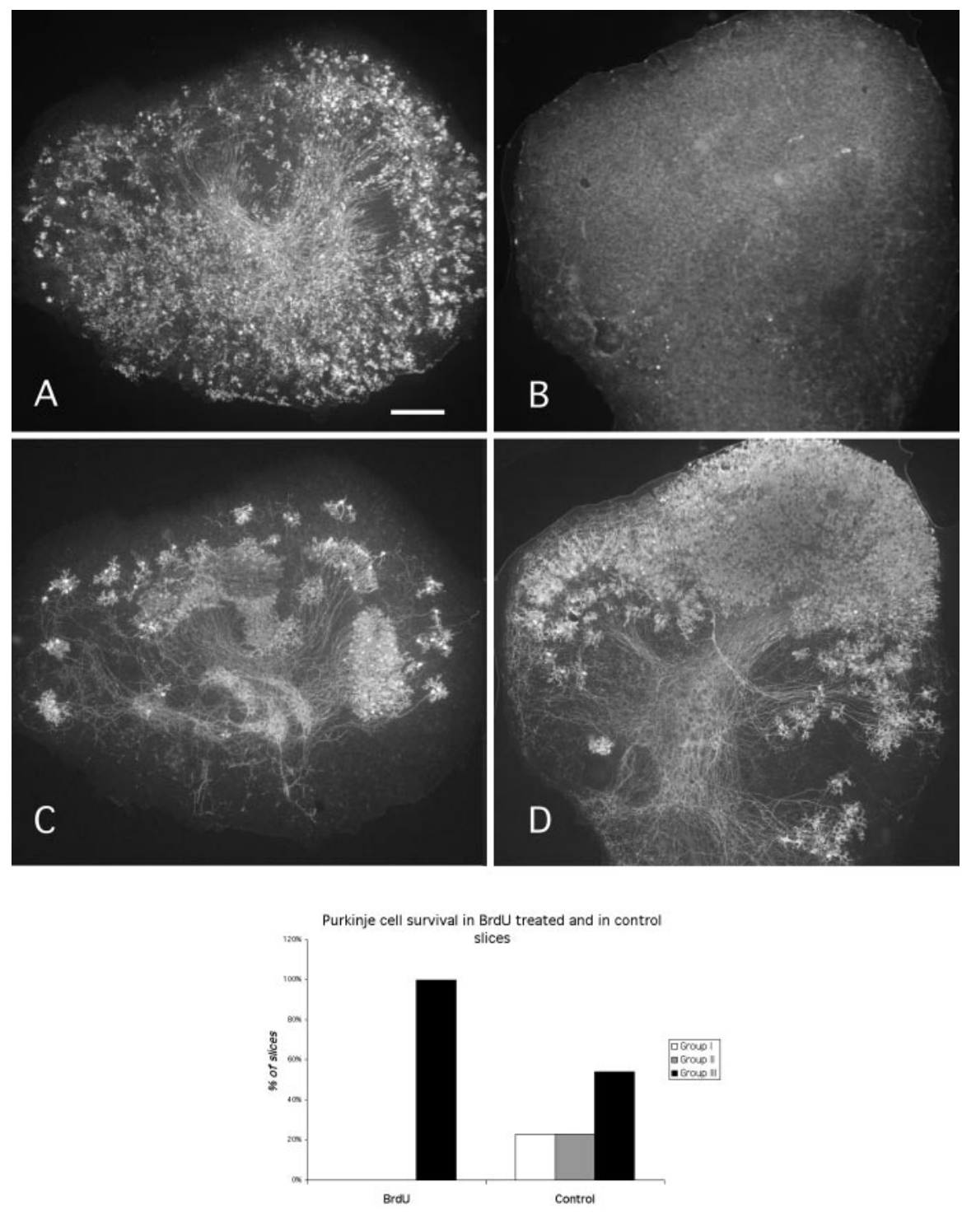

$N=4 ; n=35 \quad N=8 ; n=56$

Figure 5. BrdU treatment increases Purkinje cell survival. Photomicrographs showing P0 - 14 DIV cerebellar slices. Control $(A, C)$ and treated $(B, D)$ slices were double immunostained with anti-MBP $(A, B)$ and with anti-CaBP $(C, D)$ antibodies. $A, C$, The control slice shows numerous MBP-positive elements $(A)$ and a high rate of survival of Purkinje cells ( $C$. $B, D$, The BrdU-treated slice is devoid of myelin $(B)$, and a higher rate of Purkinje cell survival is observed $(D)$ in comparison with the control slice $(O)$. $E_{\text {, }}$ Quantitative evaluation of Purkinje cell survival. The three groups of slices (I, II, and III) were defined according to the number of Purkinje cells (see Materials and Methods). Briefly, slices with no compact group of $>20$ Purkinje cells were included in group I, slices containing one or two compact groups of $>20$ Purkinje cells in group II, and slices containing more than three compact groups of at least 20 Purkinje cells or one compact group of $>50$ Purkinje cells in group III. Note that all the BrdU-treated slices are in group III, whereas control slices are distributed in the three groups. Scale bar: $A-D, 220 \mu \mathrm{m}$.

tensively regenerated their axons within the ventral halves of the $\mathrm{CaBP}-/-$ explants (Fig. 7A). Thus, we corroborated previous results, showing that $\mathrm{P} 0$ Purkinje cells are extremely sensitive to axotomy and exhibit a great ability to regenerate their axons. However, when P0 + 7 DIV slices were processed with the same experimental protocol as $\mathrm{P} 0$ slices, and maintained in culture for 7 more days (P0 +14 DIV), the death of axotomized Purkinje cells was also massive, but the survivors completely lost their regenerative capacity (Fig. $7 B$ ). Indeed, the mean of the surface area covered by regenerative axons and the mean of the length of the longest regenerative axons drop dramatically between the slices axotomized at 0 DIV and the slices axotomized at 7 DIV 

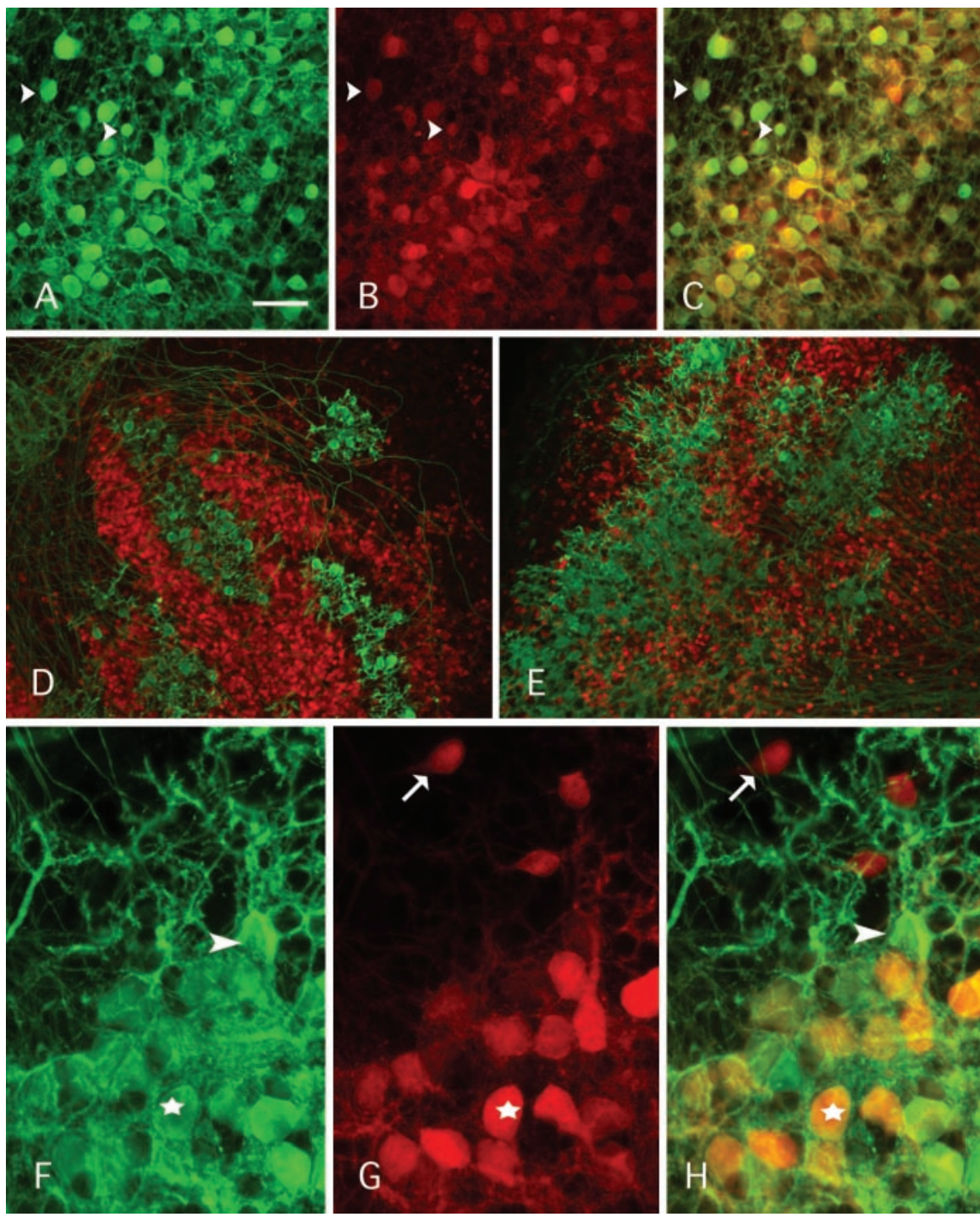

Figure 6. Photomicrographs showing P0 - 14 DIV slices double labeled with anti $C a B P / L 7(A-C)$, with anti NeuN/CaBP $(D, E)$, or with anti-parvalbumin-CaBP $(F-H)$ antibodies. $A-C$, In a BrdU-treated slice, Purkinje cells are CaBP positive $(A$, green) and $\mathrm{L} 7$ positive $(B$, red), thus appearing in yellow ( $C$ ). Note that all CaBP-positive cells are at least somewhat $L 7$ positive ( $A-C$, arrowheads). A control slice $(D)$ and a BrdU-treated slice $(E)$ double labeled with NeuN (red) and CaBP (green). Note that the number of NeuN-positive cells seems to be the same in treated and control slices. $F-H, A$ BrdU-treated slice double labeled with parvalbumin $(F$, green) and $\mathrm{CaBP}(F, G)$. Note that some Purkinje cells are only positive for $\mathrm{CaBP}$ (arrowheads), whereas some are positive for both $\mathrm{CaBP}$ and parvalbumin ( $\mathrm{F}-\mathrm{H}-$, stars). Stellate and basket cells are positive only for parvalbumin ( $F-H$, arrows). Scale bar: $\mathrm{A}-\mathrm{C}, 50$ $\mu \mathrm{m} ; D, E, 85 \mu \mathrm{m} ; F-H, 20 \mu \mathrm{m}$.

(Fig. $7 E, F)$. These results strongly suggest that (1) the developmental switch from permissive regeneration to lack of regeneration occurs in Purkinje cells maturing in vitro, and (2) the loss of regenerative capacity of these neurons is not correlated with the loss of their sensitivity to axotomy.

\section{Myelin is not the key factor in the age-dependent loss of the regenerative capacity of Purkinje cells}

To determine whether myelination occurring in the cerebellar slices is, indeed, the key factor that controls the regenerative capacity of maturing Purkinje cells, the coculture system described above was used. For these experiments, the $3 \mathrm{~d}$ treatment with BrdU was applied to both wild-type $(\mathrm{CaBP}+/+)$ and knock-out $(\mathrm{CaBP}-/-)$ cerebellar explants. We found that the BrdU treatment of slices transected at explantation (P0) and maintained in vitro for $7 \mathrm{~d}(\mathrm{P} 0+7 \mathrm{DIV})$, greatly improved the survival of axotomized Purkinje cells (Fig. 7, compare $A, C$ ), which were able to successfully regenerate their axons (Fig. 7C). Thus, BrdU treatment did not affect the regenerative capacity of immature Purkinje cells. Other P0 BrdU-treated slices were transected after 7 DIV and, in most cases, cocultured in apposition to ventral halves of BrdU-treated CaBP-/slices that were also kept in vitro for $7 \mathrm{~d}$. The cocultures were kept in vitro for an additional $7 \mathrm{~d}$. In these instances, the P0 +7 DIV axotomized Purkinje cells survived in great numbers and were much more numerous than in control slices (Fig. 7, compare $B, D$ ), after the last 7 DIV (P0 + 14 DIV). Nevertheless, despite the large number of surviving Purkinje cells that facilitated the localization of even little regenerative capacity of their axons, we were unable to observe true axonal regeneration (Fig. $7 D)$. As previously reported for control slices, the mean of the surface area covered by regenerative axons and the mean of the length of the longest regenerative axons in BrdU-treated slices also drop dramatically between P0 axotomized at 0 DIV and P0 axotomized at 7 DIV (Fig. $7 E, F$ ). However, because of the large increase in the number of surviving axotomized Purkinje cells, the areas covered with the regenerating axons were much larger than in control cultures (Fig. 7E). Thus, the developmental loss of Purkinje cell ability to regenerate their axons occurs even in the absence of myelin.

\section{Discussion}

\section{Cerebellar myelination in vivo and in vitro}

Myelination in the mouse cerebellum has been reported to begin by the end of the first postnatal week (Foran and Peterson, 1992). However, we have observed MBPpositive cells in the deep ventral cerebellum from $\mathrm{P} 3$, and by $\mathrm{P} 7$, most of the nascent white matter contained MBP-positive cells and packs of myelinated segments. Thus, myelination in the mouse, as reported previously for the rat (Reynolds and Wilkin, 1988), is an early postnatal event.

Because oligodendrocyte precursor cells are already present in the cerebellum at embryonic stages (Levine et al., 1993), myelination occurs normally in cerebellar slices taken from newborn mice. It was shown previously with electron microscopy that myelination occurs in organotypic cultures (Billings-Gagliardi et al., 1980; Seil et al., 1980; Notterpek et al., 1993).

In this study, we have shown by immunohistochemistry that the spatial development of myelination in vitro follows the same retrograde pattern (from distal axon segments to Purkinje cell bodies) observed in vivo. 


\section{In vivo and in vitro models to prevent myelination}

Models aimed at partial or total oligodendrocyte ablation have been generated previously. The in vivo models are based on the temporary destruction of most oligodendrocytes during their maturation, provoked by an antimitotic approach (for example X-irradiation of the spinal cord; Savio and Schwab, 1990), the use of specific anti-oligodendrocyte antibodies added with a complement (for example anti-galactocerebroside-C antibody injected in the spinal cord; Keirstead et al., 1992), or a transgenic approach by targeting in oligodendrocytes a toxic gene, the herpes virus 1 thymidine kinase (TK), under the control of the MBP promoter MBP-TK (Mathis et al., 2000).

The in vitro models of oligodendrocyte depletion were generally obtained by the addition of antimitotic drugs to the culture medium, for instance, BrdU (Younkin and Silberberg, 1973) or, more frequently, cytosine arabinoside (Seil et al., 1980; Stanhope et al., 1986). This approach is not specific and affects all dividing cells. Thus, the only way to increase specificity is by carefully selecting the time window of application of the antimitotic drug. BrdU application during the first $3 \mathrm{~d}$ in vitro is the shortest period allowing us to obtain P0 + 14 DIV cerebellar explants free of MBP immunoreactive elements and without myelin sheath at the ultrastructural level. Thus, proliferation of the oligodendrocyte precursor cells must be very intense during the first 3 postnatal days.

\section{Effect of BrdU treatment on the cells of the cerebellum}

Because of the lack of specificity of BrdU toxicity, it could influence all dividing cells within the P0 cerebellar slices, which consist of granule cell precursors, GABAergic interneurons, and macroglial and microglial cells. One interesting observation has been the severe decrease in the number of macrophages/activated microglial cells encountered in the treated cultures, when compared with untreated ones. The occurrence in untreated cultures of numerous microglial cells of ameboid type fits well with what we know about these cells. First, in P0 mouse CNS, almost all microglial cells are of ameboid type and show a ramified morphology only by P5 (Perry et al., 1985; Perry and Gordon, 1988). Second, it has been shown that ameboid microglial cells have a marked proliferative behavior and that the number of these cells strongly increase in the developing mouse or rat cerebellum during the early postnatal development (Ashwell, 1990; Milligan et al., 1991; Alliot et al., 1999; Marin-Teva et al., 1999; Dalmau et al., 2003).
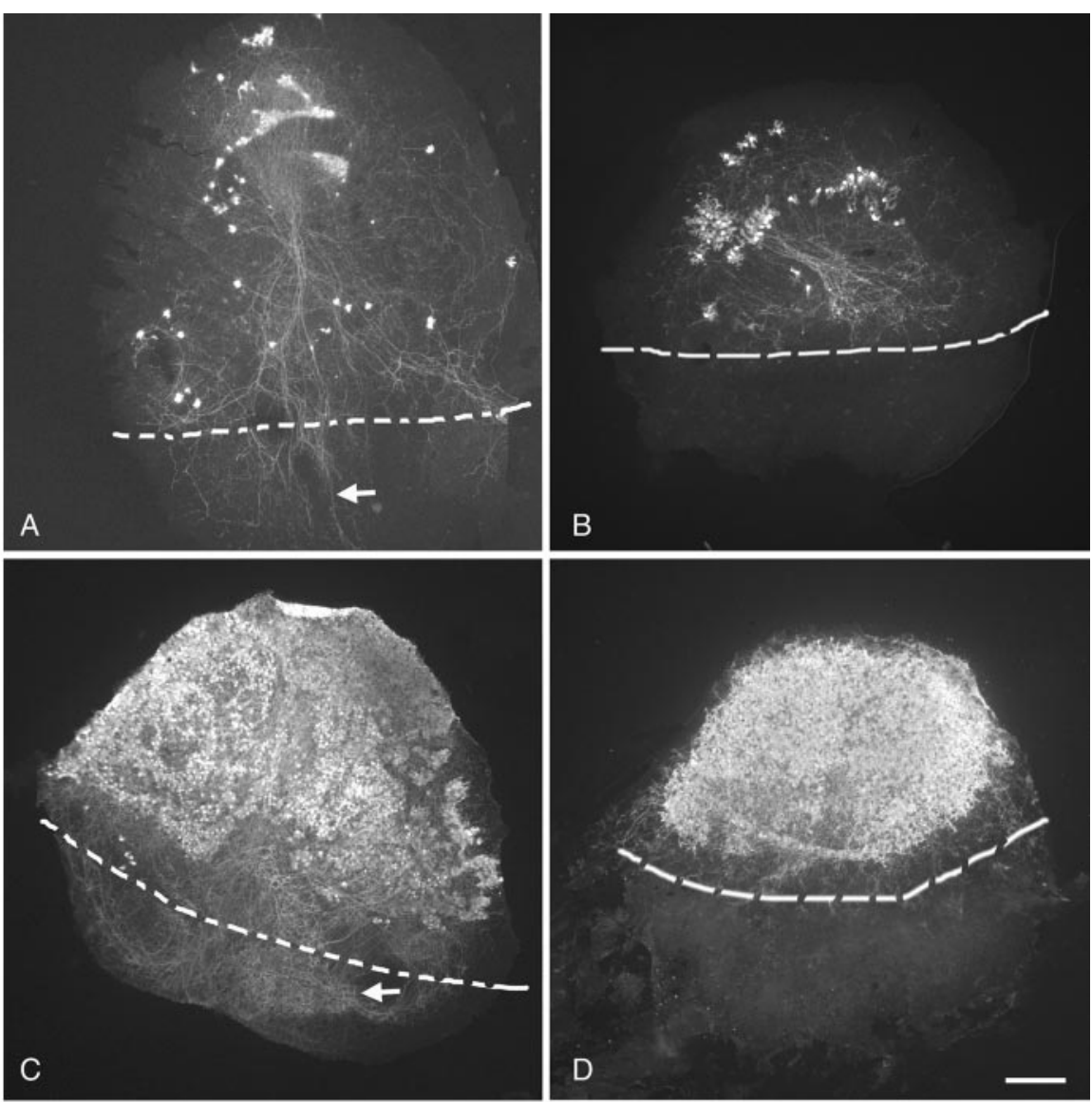

Surface of regenerative axons

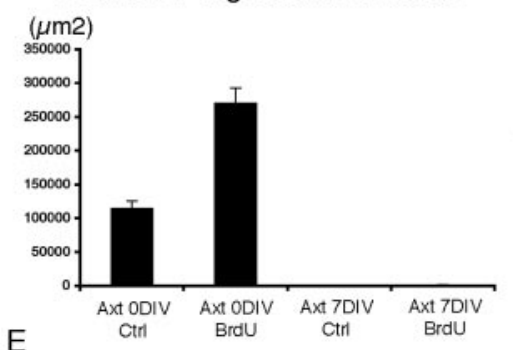

Length of the longest regenerative axons

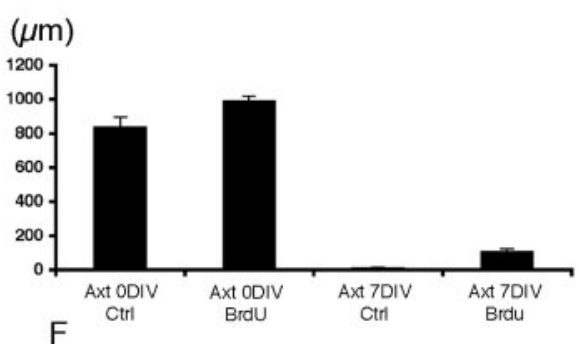

Figure 7. The absence of myelin does not favor axonal regeneration of Purkinje cells. Photomicrographs showing cocultures of the dorsal region of wild-type P0 mouse cerebellar slices with the ventral region of P0 cerebellar slices taken from a CaBP null mutant immunostained with CaBP antibodies. $A, B$, Control slices. C, D, BrdU-treated slices. The limits between the two cultures are indicated by dashed lines. $A$, The axotomy and the coculture were performed at 0 DIV. Note that the surviving Purkinje cells regenerate their axons after 7 DIV ( $A$, arrow). $B$, The axotomy and the coculture were performed at 7 DIV; the few surviving Purkinje cells did not regenerate their axons after 14 DIV. C, D, BrdU-treated cocultures. Note that BrdU treatment greatly improves the survival of axotomized Purkinje cells at 0 DIV $(C)$ and at 7 DIV $(D)$ and that, like control cocultures, Purkinje cells are able to regenerate their axons when axotomy is performed at 0 DIV $(C$, arrow) but not when axotomy is performed at 7 DIV $(D)$. $E, F$, Quantitative analysis of Purkinje cell regeneration (axon length and surface covered by regenerative axons). On each section, the surface covered by the regenerative axons (under the limit of the coculture; $A-D$, dashed line) and the longest regenerative axon were measured. $E$, Mean surface covered by regenerative axons. $F$, Mean length of the longest regenerative axon per slice in BrdU-treated slices and in control slices (Ctrl) axotomized (Axt) at 0 DIV or at 7 DIV. The measure of the surface covered by regenerative axons takes into account both regenerative axon lengths and numbers (E). Scale bar, $220 \mu \mathrm{m}$.

Furthermore, the almost complete absence of ameboid cells in P0 +7 DIV-treated cultures, in which the few existing microglial cells are of the ramified type, strongly indicates that BrdU killed all the dividing ameboid cells, sparing only those already in the process of differentiation.

The disappearance of activated microglial cells and the increase of GFAP immunoreactivity in astrocytes of the treated cultures are paradoxal. Indeed, it has been shown that microglial 
cells can stimulate reactive astrocytosis (Giulian and Robertson, 1990). Thus, the increase of GFAP immunoreactivity in the absence of activated microglial cells might result from the oligodendocytes ablation. Indeed, similar results have been observed in the MBP-TK transgenic mice in which oligodendrocytes are depleted (Mathis et al., 2000).

By far, the most numerous and actively dividing progenitor cells in the postnatal cerebellum are granule cell progenitors in the EGL. The proliferation of these progenitors starts during the last days of fetal life, although the bulk production of granule cells occurs postnatally, between P4 and P10 (Miale and Sidman, 1961; Fujita et al., 1966; Fujita, 1967). Thus, granule cell progenitors are one of the main targets of the toxic effect of high doses of BrdU in our cultures. However, in the treated cultures (14 DIV), the density of granule cells remains unchanged. Opposing results have been reported in cytosine arabinoside-treated cerebellar cultures for 5 consecutive days (Blank and Seil, 1983; Seil et al., 1983). This apparent paradox can be explained by the work of Altman et al. (1969), who analyzed the alterations taking place in the EGL after X-irradiation of the cerebellum of rat pups. They observed that after destroying a large fraction of EGL cells with several irradiations starting at birth, this proliferative layer recovers in a high proportion by P10. However, prolonged $\mathrm{X}$-irradiation prevented the regeneration of EGL cells and the formation of granule cells (Altman and Anderson, 1973). Thus, the time window of BrdU application in our cultures ( $3 \mathrm{~d}$ vs $5 \mathrm{~d}$ ) does not affect the regenerative capacity of EGL cells, explaining the maintenance of a normal granule cell density.

The robust survival effect on the Purkinje cell population observed in the BrdU-treated cultures cannot be the result of direct action of the drug. Purkinje cell proliferation in the mouse occurs between embryonic day (E) 11 and E13 (Miale and Sidman, 1961), 1 week before explantation and treatment. The indirect mechanisms leading to this survival effect, although beyond the scope of the present work, must depend on the cellular alterations induced by BrdU. For instance, a similar survival effect has been observed by Seil (1987) in cerebellar cultures treated for 5 consecutive days with cytosine arabinoside. In this case, the long period of treatment prevented any reparative process among granule cell progenitors in the EGL, and, in addition, the cultures were also depleted of astrocytes. Adding granule cells to the culture reduced the number of Purkinje cells, whereas the addition of astrocytes did not change this number (Seil, 1987). Because the granule cell density remained normal in our treated cultures (see above), and the lack of oligodendrocytes has not been related to any neuronal survival effect (Mathis et al., 2000), the absence of macrophages and activated microglial cells is one change that could explain the observed survival. Macrophages are known to promote neuronal death (Thanos, 1991; Frade and Barde, 1998). Furthermore, recent data have shown an increase of Purkinje cell survival in P3 cerebellar cultures specifically depleted of microglial cells (Marin-Teva et al., 2002). Thus, our present results emphasize the active role played by macrophages in developmental neuronal death. However, we cannot exclude that astrocytes activated by BrdU treatment could also promote Purkinje cell survival.

\section{Purkinje cell age-dependent axonal regeneration occurs in vitro and is myelin independent}

The powerful potential for axon outgrowth of immature neurons (developmental growth, sprouting, axonal regeneration) is known to decrease with maturation and to reach its end by the period of myelination. Delayed myelination by transient deple- tion of oligodendrocytes provokes a retardation in the agedependent switch from promotion to inhibition of axon regeneration (Savio and Schwab, 1990; Keirstead et al., 1992). Moreover, neutralization of myelin-associated proteins with the IN-1 antibody in the adult cerebellum induces a fast and massive sprouting of intact Purkinje cell axons (Buffo et al., 2000), whereas in postnatal cerebellum, it prevents the developmental pruning effect on immature sprouts of Purkinje cell axon intracortical plexus (Gianola et al., 2003). All these results suggest that myelin prevents all kinds of axon outgrowth and that myelinrelated molecules are involved in the developmental loss of the regeneration capability of immature axons.

We have shown previously that Purkinje cells in P0 organotypic cerebellar cultures are able to regenerate, but that they have lost this capacity in P7 cultures (Dusart et al., 1997; Ghoumari et al., 2002). Similar in vitro results have been reported in other central systems (Chen et al., 1995; Li et al., 1995; Hafidi et al., 1999). Here, we show that maturing Purkinje cells in vitro follow a time schedule similar to that in vivo, as has been seen in other neuron systems (Woodhams et al., 1993; Lohmann et al., 1999; Prang et al., 2001). This age-dependent switch observed in vitro is also independent of the amount survival of the axotomized neurons (Hafidi et al., 1999; Ghoumari et al., 2002). Indeed, although survival is enhanced, there is still no promotion of axon regeneration.

In the present study, we show that this switch is not correlated with myelination. Nevertheless, it has been reported that during development of other neuronal populations, neuronal cAMP decreases and that increasing cAMP in mature neurons overcomes their inhibition by MAG and myelin (Cai et al., 2001). In our cerebellar organotypic cultures, elevation of cAMP does not seem to prevent the Purkinje cells from switching between regeneration and lack of regeneration (our unpublished observations). Finally, the antibody blockage of NOGO does not allow mature Purkinje cell axons to regenerate in organotypic culture (Buffo et al., 2000; our unpublished data).

Our results emphasize the existence of some extrinsic or intrinsic factors, other than myelination, involved in the developmental loss of regenerative capacities. Among the extrinsic candidates that could influence Purkinje cell ability to regenerate are astrocytes. Astrocyte maturation occurs in parallel with the loss of axonal regeneration capacity (Bovolenta et al., 1984; Smith et al., 1986). It is known that, contrary to mature astrocytes, immature astrocytes are able to enhance neurite outgrowth (Smith et al., 1990; Wang et al., 1994). Furthermore, reactive astrocytes are able to produce proteoglycan molecules that are known to be inhibitors for regeneration (McKeon et al., 1991; Moon et al., 2001; Bradbury et al., 2002). In addition, because proteoglycan molecules could also be produced by oligodendrocyte precursor cells (Jones et al., 2002), they could be partially responsible of the age switch.

Concerning intrinsic factors, Goldberg et al. (2002) have shown recently that retinal maturation triggers the neonatal retinal ganglion cells to irreversibly switch from an axonal to a dendritic growth mode. This switch is mediated by signals emerging from amacrine cells. When Purkinje cells lose their capacity to regenerate their axons, they undergo their terminal phase of dendritic differentiation (Armengol and Sotelo, 1991). Thus, a similar switch from an axonal to a dendritic growth mode could occur in maturing Purkinje cells. Recently, it has been shown that inactivation of Rho promotes axonal regeneration (Lehmann et al., 1999; Dergham et al., 2002; Borisoff et al., 2003; Fournier et al., 2003; Monnier et al., 2003). Thus, it may be interesting to 
study the developmental expression pattern of small GTPbinding proteins in Purkinje cells and to test their effects on regeneration.

In conclusion, the regeneration studies reported here have confirmed that the developmental switch, which transforms highly regenerative immature Purkinje cells into mature neurons devoid of regenerative capacity, occurs in long-term cerebellar culture. Because a similar switch also occurs after experimental myelin deprivation of cerebellar slices, we can disregard myelin as a key factor for the regulation of such developmental switch in maturing Purkinje cells.

\section{References}

Airaksinen MS, Eilers J, Garaschuk O, Thoenen H, Konnerth A, Meyer M (1997) Ataxia and altered dendritic calcium signaling in mice carrying a targeted null mutation of the calbindin D28k gene. Proc Natl Acad Sci USA 94:1488-1493.

Alliot F, Godin I, Pessac B (1999) Microglia derive from progenitors, originating from the yolk sack and which proliferate in the brain. Brain Res Dev Brain Res 117:145-152.

Altman J, Anderson WJ (1973) Experimental reorganization of the cerebellar cortex. II. Effects of elimination of most microneurons with prolonged $\mathrm{x}$-irradiation started at four days. J Comp Neurol 149:123-152.

Altman J, Anderson WJ, Wright KA (1969) Early effects of x-irradiation of the cerebellum in infant rats: decimation and reconstitution of the external granular layer. Exp Neurol 24:196-216.

Armengol JA, Sotelo C (1991) Early dendritic development of Purkinje cells in the rat cerebellum. A light and electron microscopic study using axonal tracing in in vitro slices. Brain Res 64:95-114.

Ashwell K (1990) Microglia and cell death in the developing mouse cerebellum. Brain Res Dev Brain Res 55:219-230.

Billings-Gagliardi S, Adcock LH, Schwing GB, Wolf MK (1980) Hypomyelinated mutant mice. II. Myelination in vitro. Brain Res 200:135-150.

Blank NK, Seil FJ (1983) Reorganization in granuloprival cerebellar cultures after transplantation of granule cells and glia. II. Ultrastructural studies. J Comp Neurol 214:267-278.

Borisoff JF, Chan CC, Hiebert GW, Oschipok L, Robertson GS, Zamboni R, Steeves JD, Tetzlaff W (2003) Suppression of Rho-kinase activity promotes axonal growth on inhibitory CNS substrates. Mol Cell Neurosci 22:405-416.

Bovolenta P, Liem RKH, Mason CA (1984) Development of cerebellar astroglia: transitions in form and cytoskeletal content. Dev Biol 102:248-259.

Bradbury EJ, Moon LD, Popat RJ, King VR, Bennet GS, Patel PN, Fawcett JW, McMahon SB (2002) Chondroitinase ABC promotes functional recovery after spinal cord injury. Nature 416:636-640.

Buffo A, Zagrebelsky M, Huber AB, Skerra A, Schwab ME, Strata P, Rossi F (2000) Application of neutralizing antibodies against NI-35/250 myelinassociated neurite growth inhibitory proteins to the adult rat cerebellum induces sprouting of uninjured Purkinje cell axons. J Neurosci 20:2275-2286.

Cai D, Qiu J, Cao Z, McAtee M, Bregman BS, Filbin MT (2001) Neuronal cyclic AMP controls the developmental loss in ability of axons to regenerate. J Neurosci 21:4731-4739.

Cai D, Deng K, Mellado W, Lee J, Ratan R, Filbin M (2002) Arginase I and polyamines act downstream from cyclic AMP in overcoming inhibition of axonal growth MAG and myelin in vitro. Neuron 35:711.

Celio MR (1990) Calbindin D-28k and parvalbumin in the rat nervous system. Neuroscience 35:375-475.

Chen DF, Jhaveri S, Schneider GE (1995) Intrinsic changes in developing retinal neurons result in regenerative failure of their axons. Proc Natl Acad Sci USA 92:7287-7291.

Chen MS, Huber AB, van der Haar ME, Frank M, Schnell L, Spillmann AA, Christ F, Schwab ME (2000) Nogo-A is a myelin-associated neurite outgrowth inhibitor and an antigen for monoclonal antibody IN-1. Nature 403:434-439.

Cooper MH, Beal JA (1977) Myelinated granule cell bodies in the cerebellum of the monkey (Saimiri sciureus). Anat Rec 187:249-255.

Dahmane N, Ruiz-i-Altaba A (1999) Sonic hedgehog regulates the growth and patterning of the cerebellum. Development 126:3089-3100.
Dalmau I, Vela JM, Gonzales B, Finsen B, Castellano B (2003) Dynamic of microglia in the developing rat brain. J Comp Neurol 458:144-157.

Dergham P, Ellazam B, Essagian C, Avedissian H, Lubell WD, McKerracher L (2002) Rho signaling pathway targeted to promote spinal cord repair. J Neurosci 22:6570-6577.

Dusart I, Airaksinen MS, Sotelo C (1997) Purkinje cell survival and axonal regeneration are age dependent: an in vitro study. J Neurosci 17:3710-3726.

Foran DR, Peterson AC (1992) Myelin acquisition in the central nervous system of the mouse revealed by an MBP-Lac Z transgene. J Neurosci 12:4890-4897.

Fournier AE, Takizawa BT, Stittmatter SM (2003) Rho kinase inhibition enhances axonal regeneration in the injured CNS. J Neurosci 23:1416-1423.

Frade JM, Barde YA (1998) Microglia-derived nerve growth factor causes cell death in the developing retina. Neuron 20:35-41.

Fujita S (1967) Quantitative analysis of cell proliferation and differentiation in the cortex of the postnatal mouse cerebellum. J Cell Biol 32:277-287.

Fujita S, Shimada M, Nakamura T (1966) H3-thymidine autoradiographic studies on the cell proliferation and differentiation in the external and the internal granular layers of the mouse cerebellum. J Comp Neurol 128:191-208.

Ghoumari AM, Wehrle R, Bernard O, Sotelo C, Dusart I (2000) Implication of Bcl-2 and Caspase- 3 in age-related Purkinje cell death in murine organotypic culture: an in vitro model to study apoptosis. Eur J Neurosci 12:2935-2949.

Ghoumari AM, Wehrle R, De Zeeuw CI, Sotelo C, Dusart I (2002) Inhibition of protein kinase $\mathrm{C}$ prevents Purkinje cell death but does not affect axonal regeneration. J Neurosci 22:3531-3542.

Gianola S, Rossi F (2001) Evolution of the Purkinje cell response to injury and regenerative potential during postnatal development of the rat cerebellum. J Comp Neurol 430:101-117.

Gianola S, Savio T, Schwab ME, Rossi F (2003) Cell-autonomous mechanisms and myelin-associated factors contribute to the development of Purkinje axon intracortical plexus in rat cerebellum. J Neurosci 23:4613-4624.

Giulian D, Robertson C (1990) Inhibition of mononuclear phagocytes reduces ischemic injury in the spinal cord. Ann Neurol 27:33-42.

Goldberg JL, Klassen MP, Hua Y, Barres BA (2002) Amacrine-signaled loss of intrinsic axon growth ability by retinal ganglion cells. Science 296:1860-1864.

GrandPre T, Nakamura F, Vartanian T, Strittmatter SM (2000) Identification of the Nogo inhibitor of axon regeneration as a Reticulon protein. Nature 403:439-444.

Hafidi A, Lanjun G, Sanes DH (1999) Age-dependent failure of axon regeneration in organotypic culture of gerbil auditory midbrain. J Neurobiol 41:267-280.

Hasan SJ, Keirstead HS, Muir GD, Steeves JD (1993) Axonal regeneration contributes to repair of injured brainstem-spinal neurons in embryonic chick. J Neurosci 13:492-507.

Jones A, Korpi ER, McKernan RM, Pelz R, Nusser Z, Makela R, Mellor JR, Pollard S, Bahn S, Stephenson FA, Randall AD, Sieghart W, Somogyi P, Smith AJ, Wisden W (1997) Ligand-gated ion channel subunit partnerships: GABAA receptor $\alpha 6$ subunit gene inactivation inhibits delta subunit expression. J Neurosci 17:1350-1362.

Jones LL, Yamaguchi Y, Stallcup WB, Tusynski MH (2002) NG2 is a major chondroitin sulfate proteoglycan produced after spinal cord injury and is expressed by macrophages and oligodendrocyte progenitors. J Neurosci 22:2792-2803.

Keirstead HS, Hasan SJ, Muir GD, Steeves JD (1992) Suppression of the onset of myelination extends the permissive period for the functional repair of embryonic spinal cord. Proc Natl Acad Sci USA 89:11664-11668.

Lehmann M, Fournier A, Selles Navarro I, Dergham P, Sebok A, Leclerc N, Tigyi G, McKerracher L (1999) Inactivation of Rho signaling pathway promotes CNS axon regeneration. J Neurosci 19:7537-7547.

Levine JM, Stincone F, Lee YS (1993) Development and differentiation of glial precursor cells in the rat cerebellum. Glia 7:307-321.

Li D, Field PM, Raisman G (1995) Failure of axon regeneration in postnatal rat entorhinohippocampal slice coculture is due to maturation of the axon, not that of the pathway or target. Eur J Neurosci 7:1164-1171.

Lohmann C, Ehrlich I, Friauf E (1999) Axon regeneration in organotypic slice cultures from the mammalian auditory system is topographic and functional. J Neurobiol 41:596-611.

Marin-Teva JL, Almendros A, Calvente R, Cuadros MA, Navascues J (1999) 
Proliferation of actively migrating ameboid microglia in the developing quail retina. Anat Embryol 200:289-300.

Marin-Teva JL, Dusart I, Colin C, Gervais A, Van Rooijen N, Mallat M (2002) Selective elimination of microglial cells in organotypic cultures: a new model to study microglial functions. Glia S1:S15.

Mathis C, Hindelang C, LeMeur M, Borrelli E (2000) A transgenic mouse model for inducible and reversible dysmyelination. J Neurosci 20:7698-7705.

McKeon RJ, Schreiber RC, Rudge JS, Silver J (1991) Reduction of neurite outgrowth in a model of glial scarring following CNS injury is correlated with the expression of inhibitory molecules on reactive astrocytes. J Neurosci 11:3398-3411.

McKerracher L, David S, Jackson DL, Kottis V, Dunn RJ, Braun PE (1994) Identification of myelin-associated glycoprotein as a major myelinderived inhibitor of neurite growth. Neuron 13:805-811.

Mellor JR, Merlo D, Jones A, Wisden W, Randall AD (1998) Mouse cerebellar granule cell differentiation: electrical activity regulates the GABAA receptor $\alpha 6$ subunit gene. J Neurosci 18:2822-2833.

Miale IL, Sidman RL (1961) An autoradiographic analysis of histogenesis in the mouse cerebellum. Exp Neurol 4:277-296.

Milligan CE, Cunningham TJ, Levitt P (1991) Differential immunochemical markers reveal the normal distribution of brain macrophages and microglia in the developing rat brain. J Comp Neurol 314:125-135.

Monnier PP, Sierra A, Schwab JM, Henke-Fahle S, Mueller BK (2003) The Rho/ROCK pathway mediates neurite growth-inhibitory activity associated with the chondroitin sulfate proteoglycans of the CNS glial scar. Mol Cell Neurosci 22:319-330.

Moon LD, Asher RA, Rhodes KE, Fawcett JW (2001) Regeneration of CNS axons back to their target following treatment of adult rat brain with chondroitinase ABC. Nat Neurosci 4:465-466.

Mukhopadhyay G, Doherty P, Walsh FS, Crocker PR, Filbin MT (1994) A novel role for myelin-associated glycoprotein as an inhibitor of axonal regeneration. Neuron 13:757-767.

Mullen RJ, Buck CR, Smith AM (1992) NeuN, a neuronal specific nuclear protein in vertebrates. Development 116:201-211.

Notterpek LM, Bullock PN, Malek-Hedayat S, Fisher R, Rome LH (1993) Myelination in cerebellar slice cultures: development of a system amenable to biochemical analysis. J Neurosci Res 36:621-634.

Oberdick J, Levinthal F, Levinthal C (1988) A Purkinje cell differentiation marker shows a partial DNA sequence homology to the cellular sis/ PDGF2 gene. Neuron 1:367-376.

Perry VH, Gordon S (1988) Macrophages and microglia in the nervous system. Trends Neurosci 11:273-277.

Perry VH, Hume DA, Gordon S (1985) Immunohistochemical localization of macrophages and microglia in the adult and developing mouse brain. Neuroscience 15:313-326.

Pesheva P, Probstmeier R (2000) Association of tenascin-R with murine brain myelin membranes: involvement of divalent cations. Neurosci Lett 283:165-168.
Prang P, Del Turco D, Kapfhammer JP (2001) Regeneration of entorhinal fibers in mouse slice cultures is age dependent and can be stimulated by NT-4, GDNF, and modulators of G-proteins and protein kinase C. Exp Neurol 169:135-147.

Prinjha R, Moore SE, Vinson M, Blake S, Morrow R, Christie G, Michalovich D, Simmons DL, Walsh FS (2000) Inhibitor of neurite outgrowth in humans. Nature 403:383-384.

Reynolds R, Wilkin GP (1988) Development of macroglial cells in rat cerebellum. II. An in situ immunohistochemical study of oligodendroglial lineage from precursor to mature myelinating cell. Development 102:409-425.

Savio T, Schwab ME (1990) Lesioned corticospinal tract axons regenerate in myelin-free rat spinal cord. Proc Natl Acad Sci USA 87:4130-4133.

Schwab ME, Bartholdi D (1996) Degeneration and regeneration of axons in the lesioned spinal cord. Physiol Rev 76:319-370.

Seil FJ (1987) Enhanced Purkinje cell survival in granuloprival cerebellar cultures. Brain Res 432:312-316.

Seil FJ, Leiman AL, Woodward WR (1980) Cytosine arabinoside effects on developing cerebellum in tissue culture. Brain Res 186:393-408.

Seil FJ, Leiman AL, Blank NK (1983) Reorganization in granuloprival cerebellar cultures after transplantation of granule cells and glia. I. Light microscopic and electrophysiological studies. J Comp Neurol 214:258-266.

Smith GM, Miller RH, Silver J (1986) Changing role of forebrain astrocytes during development, regenerative failure, and induced regeneration upon transplatation. J Comp Neurol 251:23-43.

Smith GM, Rutishauser U, Silver J, Miller RH (1990) Maturation of astrocytes in vitro alters the extent and molecular basis of neurite outgrowth Dev Biol 138:377-390.

Stanhope GB, Wolf MK, Billings-Gagliardi S (1986) Genotype-specific myelin formation around normal axons in cytosine arabinoside-treated organotypic cultures injected with normal or shiverer optic nerve. Brain Res 389:109-116.

Stoppini L, Buchs PA, Muller D (1991) A simple method for organotypic cultures of nervous tissue. J Neurosci Methods 37:173-182.

Streit WS, Kreutzberg GW (1987) Lectin binding by resting and reactive microglia. J Neurocytol 16:249-260.

Thanos S (1991) The relationship of microglial cells to dying neurons during natural neuronal cell death and axotomy-induced degeneration of the rat retina. Eur J Neurosci 3:1189-1207.

Wang KC, Koprivica V, Kim JA, Sivasankaran R, Guo Y, Neve RL, He Z (2002) Oligodendrocyte-myelin glycoprotein is a Nogo receptor ligand that inhibits neurite outgrowth. Nature 417:941-944.

Wang LC, Baird DH, Hatten ME, Mason CA (1994) Astroglial differention is required for support of neurite outgrowth. J Neurosci 14:3195-3207.

Woodhams PL, Atkinson DJ, Raisman G (1993) Rapid decline in the ability of entorhinal axons to innervate the dentate gyrus with increasing time in organotypic co-culture. Eur J Neurosci 5:1596-1609.

Younkin L, Silberberg D (1973) Myelination in developing cultured newborn rat cerebellum inhibited by 5-bromodeoxyuridine. Exp Cell Res 76:455-458. 